\title{
SEISMOGENIC SOURCES IN THE AEGEAN AREA AND THEIR PREDICTIVE PROPERTIES
}

\author{
Papazachos B.C. ${ }^{1}$, Karakaisis G.F. ${ }^{1}$, Scordilis E.M. ${ }^{1}$ and Papaioannou Ch.A. ${ }^{2}$ \\ ${ }^{1}$ Aristotle University of Thessaloniki, Department of Geology, 54124, Thessaloniki, Greece, \\ bpapaza@geo.auth.gr,karakais@geo.auth.gr,manolis@geo.auth.gr \\ ${ }^{2}$ EPPO-ITSAK, P.O. Box 53 Finikas, 55102, Thessaloniki, Greece, chpapai@itsak.gr
}

\begin{abstract}
On the basis of all available information eight circular seismogenic sources, where shallow $(h \leq 100 \mathrm{~km})$ earthquakes occur, are defined in the broader Aegean area. The location of each source is further improved by optimization of the quasi-periodic properties of the strong $(M \geq 6.0)$ instrumentally recorded mainshocks, identified in a complete catalogue of earthquakes (1911-2014) after declustering. Moreover, in the same seismogenic sources, all $M \geq 6.3$ mainshocks that comprise another complete catalogue (1850-2014) have also occurred. Interevent times of mainshocks generated in each source have predictive properties expressed by the TIMAPR (Time and Magnitude Predictable Regional) model whereas preshocks of recent mainshocks have also such properties expressed by the D-AS (Decelerating-Accelerating Seismicity) model. Retrospective prediction of the last mainshock in each source by the joint application of the two models resulted in reasonable uncertainties. Then, as a forward test, data up to the end of 2014 were used to predict the next expected mainshock in each of the eight sources and to identify the fault where its epicentre will probably be located.
\end{abstract}

Keywords: Seismogenic sources, Preshocks, Aegean.

\section{Пєрí $\eta \Psi \eta$}

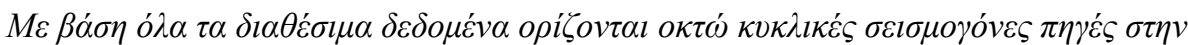

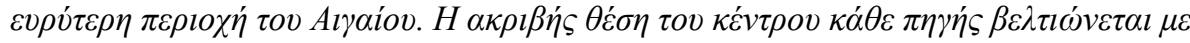

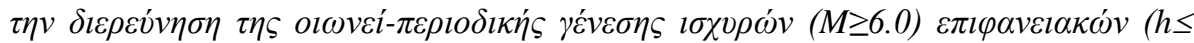

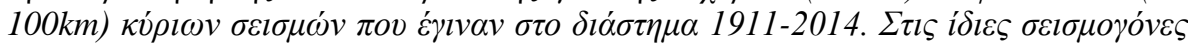

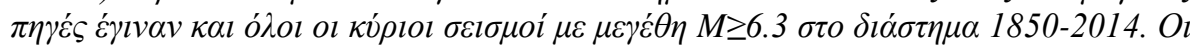

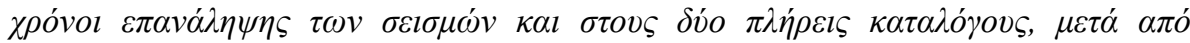

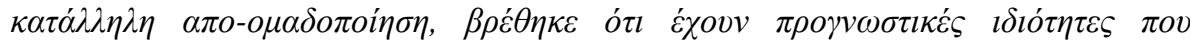

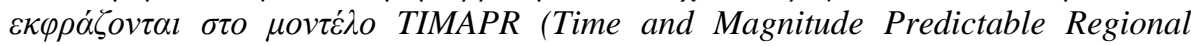

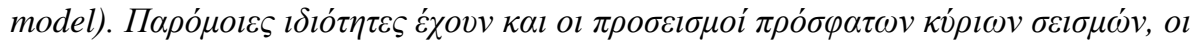

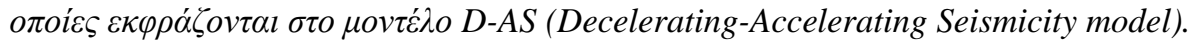

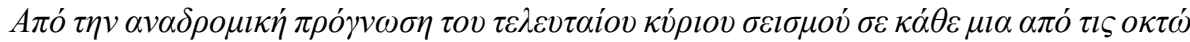

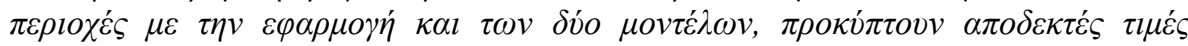

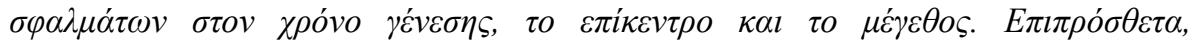

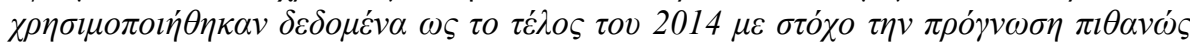

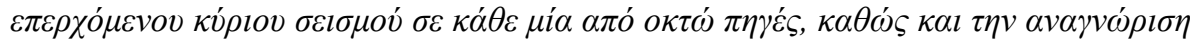

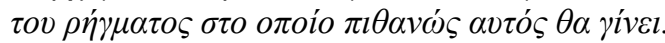

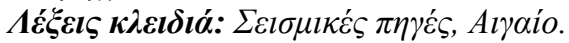




\section{Introduction}

Prediction of strong $(M \geq 6.0)$ earthquakes is of primary social importance for areas with high seismicity, like Greece and other countries in the broader Aegean area $\left(34^{\circ}-42^{\circ} \mathrm{N}, 19^{\circ}-28^{\circ} \mathrm{E}\right)$. Such prediction, however, is a very difficult scientific problem. Thus, intense international effort of about three decades (1960-1990) for short-term earthquake prediction (with time-window up to a few days) did not lead to important positive results. During the same time period, less scientific effort has been made for long-term earthquake prediction (time window of a few decades, probably because its social importance is similar to that of the existing scientific knowledge on the space variation of seismicity, which is currently applied in facing important social problems (e.g. seismic zonation applied in seismic codes, etc.). Scientific work on intermediate term earthquake prediction (time window in years up to a decade) is currently intensively carried out (e.g. Jaumè and Sykes, 1999; Mignan, 2011 and references therein), because it is scientifically promising and its results can be effectively applied for taking early pre-mainshock protection measures.

The goal of the present work is to locate seismogenic sources (networks of active seismic faults) in the broader Aegean area and define their predictive properties, in order to perform, in each of these sources, backward and forward predictive tests of two time-dependent seismicity models. The one of these models is based on predictive properties of the interevent times of the strong mainshocks located in each seismogenic source. This is called TIMAPR (Time and Magnitude Predictable Regional) model (Papazachos et al., 2011). The other is based on triggering of each strong mainshock by a decelerating and an accelerating precursory seismic sequence and is called D-AS (Decelerating-Accelerating Seismicity) model (Papazachos et al., 2006). Data used for application of the TIMAPR model are those included in the two most recent complete samples of strong earthquakes [a) 1911-2014, $M \geq 6.0$; b) 18502014, $M \geq 6.3$. The data used for application of the D-AS model are included in an instrumental catalogue of this area, which is complete for the period 1965-2014 for $M \geq 4.3$ (when a dense network of seismological stations has been in operation in the Aegean area).

\section{Seismogenic sources in the Aegean area}

From instrumental and historical seismological data and from geological observations, it can be observed that strong $(M \geq 6.0)$ earthquakes are not generated everywhere in the broader Aegean area (Aegean Sea and its surroundings) but in certain seismogenic zones which include networks (systems) of large active seismic faults. Global observations also show that strong mainshocks are generated only in such seismogenic zones and follow relations $(1,2)$ of the TIMAPR model (Papazachos et al., 2014). The decelerating preshocks (a seismic excitation followed by seismic quiescence), which precede strong mainshocks, are also generated in these seismogenic sources.

Identification of seismogenic sources, which are considered circular in the present work, and investigation of their properties are feasible by known scientific procedures and available datasets. Such work can contribute much to the intermediate-term prediction (time window of one decade) of strong earthquakes because strong future earthquakes will be also generated in already defined and investigated seismogenic sources.

To define circular seismogenic sources in the broader Aegean area, a procedure of two steps was followed. In the first step, all available relative geophysical and geological information were used to define the existing seismogenic zones in the Aegean. This information includes: the geographical distribution of all known strong $(M \geq 6.0)$, shallow, accurately located earthquakes with $h \leq 100 \mathrm{~km}$, the geographical distribution and properties of all known active seismic faults (Papazachos et. al, 2001), the type of lithospheric plate movements (McKenzie, 1970; Papazachos and Comninakis, 1971), as well as previously published information on seismotectonic zonation in the Aegean area (Karakaisis et al., 2010). The selection criterion for $\mathrm{h} \leq 100 \mathrm{~km}$-was based on the observation since 70's that the damage pattern and intensity values of the intermediate depth earthquakes in Southern Greece are much higher than might be expected for such events. A possible explanation is that the 
faulting of these type events extends upward to much shallower depths than indicated by the instrumental depth (Algermissen et al., 1976).

In the second step, the instrumental complete earthquake catalogue (1911-2014, $M \geq 6.0)$ is used to define the center, $K$, and the radius, $r$ (in $\mathrm{km}$ ), of each of the eight circular seismogenic sources where corresponding mainshocks (resulted from proper declustering procedure of the original complete catalogue) are located. The origin times and magnitudes of the mainshocks of a seismogenic source fit relations 1 and 2 of the TIMAPR model and the degree of fit of relation 1 is expressed by an optimization parameter, $O P$ (section 3.1). Thus, in order to define a circular seismogenic source with center in the corresponding seismotectonic zone of the Aegean area, each zone is covered by a dense grid of geographic points. Each point of the grid is considered as probable center of a candidate circular seismogenic source and circles with increasing radii in small steps (e.g. $10 \mathrm{~km})$ are defined. The complete catalogue of the earthquakes located within each such circle is declustered to define the mainshocks located in it. The parameters of the mainshocks of each circle are used to calculate the value of the corresponding optimization parameters. Of all circular regions, with radius $\leq 200 \mathrm{~km}$, considered as candidate seismogenic sources, the one with the highest value of the optimization parameter, $O P$, is accepted as the circular seismogenic source.

Table 1 gives information on the location and other properties of the eight circular seismogenic sources of the broader Aegean Area. Each seismogenic source is a part of the lithosphere which includes systems (networks) of large seismic faults. These seismic faults have been very active for long time in the past and are also expected to be equally active in the future.

Almost all strong $(M \geq 6.0)$ earthquakes which occurred in Greece during the time period 1965-2014 (when location and magnitudes are accurately determined due to the continuous operation of a dense seismological network) are located in these eight (8) circular seismogenic sources defined in the present work. Also, of the 66 large $(M \geq 7.0)$ earthquakes that occurred in the Aegean since 1.1.1600, 62 were located in these eight circular seismogenic sources and only 4 are out of these sources (due, probably, to location errors). This supports our hypothesis that strong future earthquakes must be also expected in these eight circular seismogenic sources.

Each of the eight circular seismogenic sources has been finally defined in the Aegean area on the basis of periodic properties of mainshocks located in each of these sources (Figure 1). However, the seismicity level (epicenter density of strong shocks) is higher in the inner part of each source (around its center). Both the best available complete instrumental sample of strong earthquakes (1911-2014, $M>6.0)$ as well as the most reliable and recent such sample (1965-2014, $M \geq 5.5)$ show that the epicenter density is high in the inner circle (with center, $K_{i}$, of the $i$-th seismogenic source and radius $100 \mathrm{~km})$ and low in the outer $(100-200 \mathrm{~km})$ part. Figure 2 shows the cumulative value, $N(\leq x)$, of the mean epicenter density of the strong earthquakes $(M \geq 6.0,1911-2014)$ of all eight seismogenic sources, as a function of the distance, $x$ (in $\mathrm{km}$ ), from the center of the corresponding seismogenic source. This figure shows clearly two zones with different seismicity levels: one circular (0-100km) seismic zone with high epicenter density $(\sim 0.4$ rate with distance from the center of the seismogenic source) and the other (100-200km) with low (background) seismicity as it comes out from the low epicenter density ( 0.2 rate). Figure 1 shows the eight circular seismogenic sources (dashed line circles) and their inner active parts (solid line circles).

The observation that all these eight inner seismicity zones of the Aegean area have almost equal horizontal dimensions (radius $\sim 100 \mathrm{~km}$ ) is not surprising, because these dimensions depend on the maximum length of the active parts of the faults which are expected to generate maximum earthquakes of similar magnitudes in each circular seismogenic source. Observations showed that the magnitudes of the largest earthquakes in each of the eight inner circular seismicity zones are similar (the average maximum magnitude with its standard deviation of these eight largest earthquakes is $7.1 \pm 0.3)$. 
Table 1 - Information on the eight circular seismogenic sources (networks of seismic faults) in the Aegean sea and its surroundings. The first two columns show the code numbers, $n$, and the names of the seismogenic sources. All data used have been instrumentally recorded

(1911-2014) and are complete $\left(M_{\min } \geq 6.0\right)$. The third and fourth columns give the geographical coordinates of the center, $K(\varphi, \lambda)$, and the radius, $\mathbf{r}$ (in $\mathbf{k m})$, of each circular seismogenic source. In the next column the values of the optimization parameter, OP, are given, and the last four columns give the mean values of the constants $q$ and $w$ of relations 1 and 2 and their standard deviations $\left(\sigma_{q}, \sigma_{\mathrm{w}}\right)$, respectively.

\begin{tabular}{|c|l|c|c|c|c|c|c|c|}
\hline $\mathbf{n}$ & Source Name & $\mathbf{K}(\boldsymbol{\varphi}, \boldsymbol{\lambda})$ & $\mathbf{r}(\mathbf{k m})$ & $\mathbf{O P}$ & $\mathbf{q}$ & $\boldsymbol{\sigma}_{\mathbf{q}}$ & $\mathbf{w}$ & $\boldsymbol{\sigma}_{\mathbf{w}}$ \\
\hline 1 & NW. Greece & $40.5,20.7$ & 120 & 14 & 1.50 & 0.19 & 0.75 & 0.24 \\
\hline 2 & Ionian Sea & $38.3,20.2$ & 150 & 53 & 1.30 & 0.05 & 1.13 & 0.24 \\
\hline 3 & W. Hellenic Arc & $36.0,22.5$ & 200 & 14 & 1.42 & 0.17 & 0.95 & 0.28 \\
\hline 4 & E. Hellenic Arc & $36.0,26.5$ & 200 & 11 & 1.48 & 0.16 & 1.06 & 0.31 \\
\hline 5 & E. Centr. Greece & $39.0,22.9$ & 150 & 27 & 1.48 & 0.09 & 0.91 & 0.20 \\
\hline 6 & E. Aegean & $38.0,27.0$ & 120 & 35 & 1.58 & 0.05 & 1.24 & 0.45 \\
\hline 7 & Serbomacedonia & $41.0,23.0$ & 150 & 14 & 1.46 & 0.22 & 1.15 & 0.34 \\
\hline 8 & NE. Aegean & $39.6,26.6$ & 160 & 43 & 1.33 & 0.09 & 1.21 & 0.25 \\
\hline
\end{tabular}

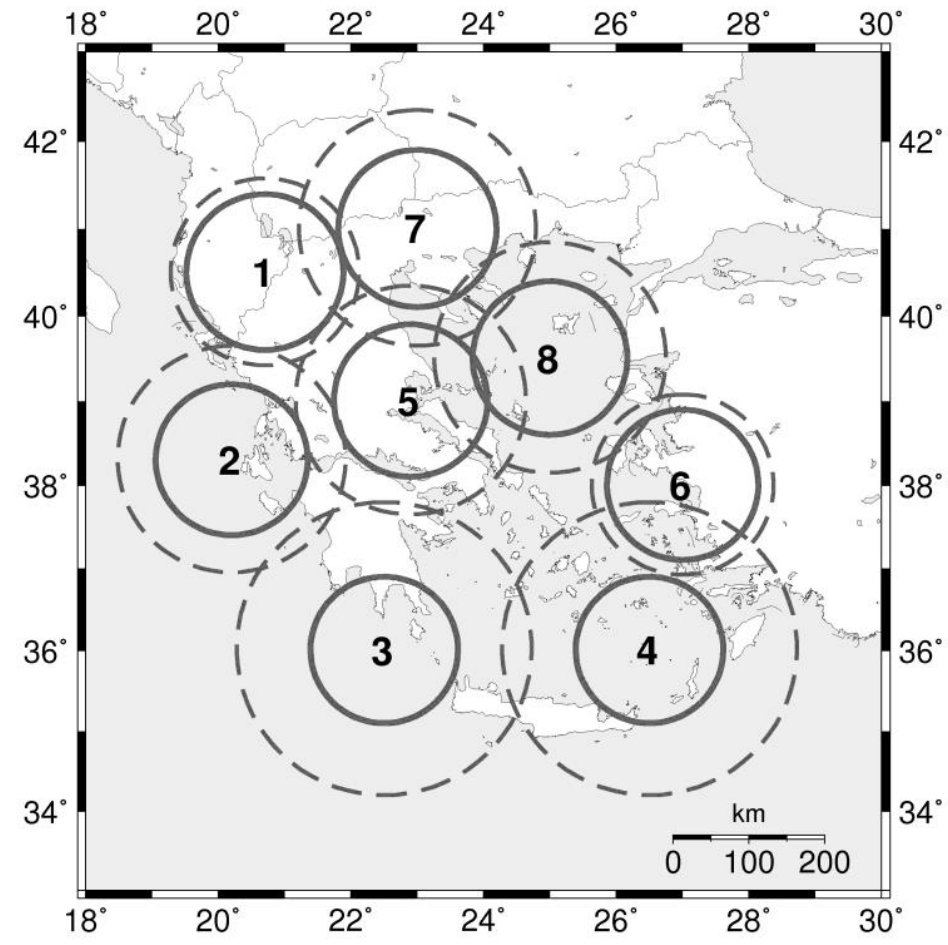

Figure 1 - The eight circular $\left(K_{i}, r=100 \mathrm{~km}\right)$ regions of high seismicity (solid line circles) which form the inner parts of the corresponding eight circular seismogenic sources (dashed line circles) of the Aegean. The numbers correspond to the code-numbers of these sources for which detailed information is given in Table 1. 


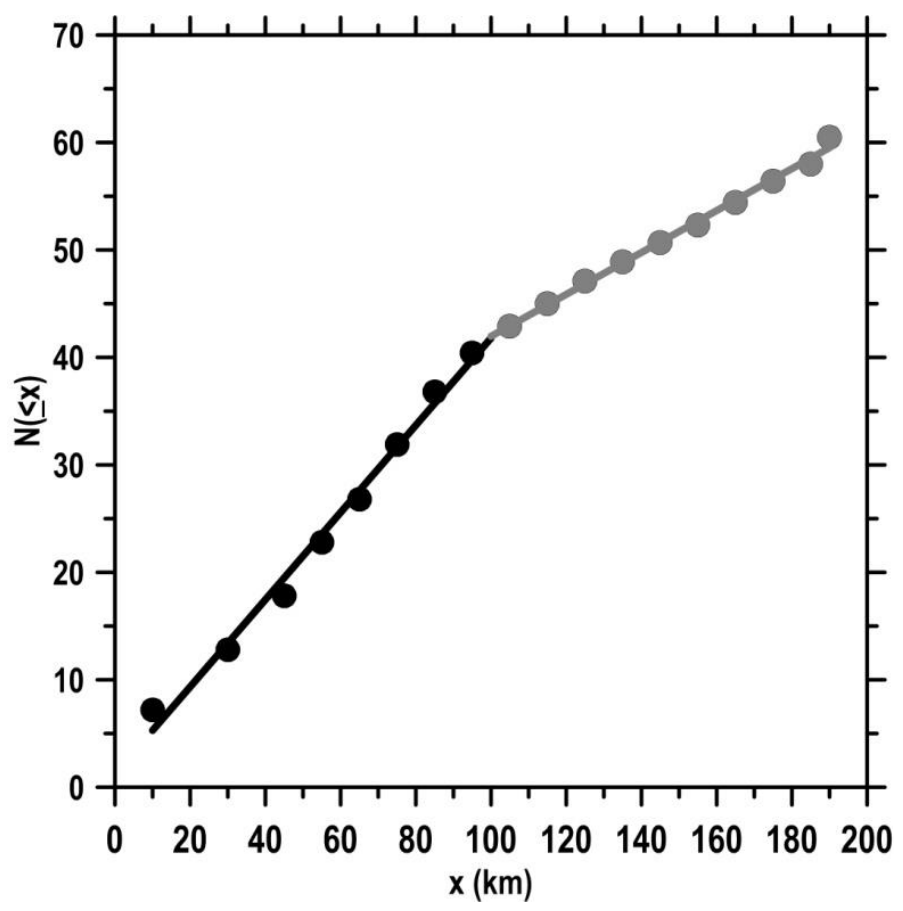

Figure 25 - Variation of the cumulative density, $N(\leq x)$, of the mean epicenter density (number of epicenters per $10^{3} \mathrm{~km}^{2}$ ) of the instrumentally located strong earthquakes (19112014, $M \geq 6.0$ ) in the broader Aegean area, with the distance, $x$ (in $\mathrm{km}$ ), from the center of the corresponding seismogenic source. It is clear that the epicenter density is very high in the inner $(0-100 \mathrm{~km})$ circular part of the seismogenic sources $($ rate $=0.41)$ and is much reduced in the outer $(>100 \mathrm{~km})$ parts $($ rate $=\mathbf{0 . 2 0})$ which are dominated by background seismicity.

\section{Predictive properties of the two time dependent seismicity models}

The TIMAPR and the D-AS models have been developed during the last two decades and details on their properties are given in published papers cited in the present work. In the present section, the procedure followed for the application of the two models is described and backward tests are made to estimate the uncertainties of the parameters calculated by these models. Forward tests are also performed by the joint application of the two time dependent models, in an attempt to predict the probably expected next mainshock in each of the eight seismogenic sources of the broader Aegean area.

\subsection{The TIMAPR model}

This model has been developed by the use of information on earthquakes of original (complete) catalogues concerning a large number of global seismogenic sources (Papazachos et al., 2014). Each complete catalogue is declustered so that the remaining earthquakes (mainshocks) to fulfil the condition: $(\sigma / T)<0.50$, where $T$ is the mean return period of the mainshocks of a seismogenic source and $\sigma$ is its standard deviation, that is, the mainshocks to exhibit a quasi-periodic behavior (Kagan and Jackson, 1991). The ratio $\sigma / T$ decreases with increasing declustering time-window, $\Delta t$. For $\Delta t \geq 15.0$ years this ratio becomes small and remains almost constant $(\sim 0.30)$. In this way, a large number of complete global samples of mainshocks had been available and were used to derive the following two relations of global validity:

\section{Equation 1}

$\log \mathrm{T}_{\mathrm{t}}=0.19 \mathrm{M}_{\min }+0.33 \mathrm{M}_{\mathrm{p}}-0.54 \log \mathrm{S}_{\mathrm{d}}+\mathrm{q}$ 


\section{Equation 2}

$\mathrm{M}_{\mathrm{f}}=0.73 \mathrm{M}_{\min }-0.28 \mathrm{M}_{\mathrm{p}}+0.48 \log \mathrm{S}_{\mathrm{d}}+\mathrm{w}$

where $T_{t}$ (in years) is the interevent time, $M_{p}$ is the magnitude of the previous mainshock in the seismogenic source, $M_{f}$ is the magnitude of the following mainshock in this source, $M_{\min }$ is the minimum mainshock magnitude and $S_{d}\left(\right.$ in $J^{1 / 2} / y r$ ) is the annual rate of the Benioff strain. The average values of $\mathrm{q}$ and $\mathrm{w}$ and their standard deviations $\left(\sigma_{\mathrm{q}}, \sigma_{\mathrm{w}}\right)$ are calculated (by equations 1 and 2 and by using the respective complete data for each of the eight seismogenic sources of the Aegean area). The ratio $T / T_{t}$ of the observed time, $T$, to the calculated (by equation 1 ) time, $T_{t}$, follows a lognormal distribution with mean equal to zero and a standard deviation, $\sigma$ (e.g. Papazachos and Papaioannou, 1993), which allows the calculation of the probability, $\mathrm{P}(\Delta \mathrm{t})$, for the occurrence of a mainshock with $\mathrm{M} \geq \mathrm{M}_{\min }$ during the next $\Delta \mathrm{t}$ years if the previous mainshock occurred in the seismogenic source $\mathrm{t}$ years ago. The optimization parameter, $O P$, for the selection of the circle $(\mathrm{K}, \mathrm{r})$ is given by the relation $O P=\mathrm{N}^{1 / 2} / \sigma_{\mathrm{q}}$, where $\mathrm{N}$ is the number of the interevent times of the mainshocks located in the corresponding seismogenic source and $\sigma_{q}$ is the standard deviation of $q$ of equation 1 . The best solution is obtained when $O P$ takes its maximum value with $\mathrm{N} \geq 3$ and is used for the prediction of the probably ensuing mainshock. Thus, for this model, as epicenter, $\mathrm{E}_{\mathrm{t}}$, of an ensuring mainshock is considered the geographic mean (mean latitude, mean longitude) of the past known mainshocks located in the seismogenic source, its magnitude, $\mathrm{M}_{\mathrm{t}}$, is the $\mathrm{M}_{\mathrm{f}}$ calculated by equation 2 and its origin time, $\mathrm{t}_{\mathrm{t}}$, results by adding the interevent time, $\mathrm{T}_{\mathrm{t}}$ (equation 1 ), to the origin time of the last mainshock.

\subsection{The D-AS model}

This model requires the identification of a relatively small circular (seismogenic) region where decelerating preshocks are generated and another larger circular (critical) region where accelerating preshocks are generated. The cumulative Benioff strain, $S$ (in $\mathrm{J}^{1 / 2}$ ), of the preshocks of a mainshock is given by the power law relation:

\section{Equation 3}

$\mathrm{S}(\mathrm{t})=\mathrm{A}+\mathrm{B}\left(\mathrm{t}_{\mathrm{c}}-\mathrm{t}\right)^{\mathrm{m}}$

where, $t_{c}$ is the origin time of the mainshock, $t$ is the time to the mainshock and $A, B, m$ are parameters calculated by the available instrumental relative data (Bufe and Varnes, 1993), with $\mathrm{m}<1$ (e.g. $\mathrm{m}=0.30$ ) for accelerating preshocks and $\mathrm{m}>1$ (e.g. $\mathrm{m}=3.0$ ) for decelerating preshocks.

The radius, $\mathrm{r}$ (in $\mathrm{km}$ ), of the circular seismogenic region and, $\mathrm{R}$ (in $\mathrm{km}$ ), of the circular critical region are given by the relations:

\section{Equation 4}

$\log r=0.23 \mathrm{M}-0.14 \log _{\mathrm{d}}+1.40 \quad \sigma=0.15$

\section{Equation 5}

$\log \mathrm{R}=0.42 \mathrm{M}-0.30 \log _{\mathrm{a}}+1.25 \quad \sigma=0.16$

where, $\mathrm{M}$ is the mainshock magnitude and $\mathrm{s}_{\mathrm{d}}$ and $\mathrm{s}_{\mathrm{a}}\left(\mathrm{in} \mathrm{J}^{1 / 2} / \mathrm{yr} .10^{4} \mathrm{~km}^{2}\right.$ ) are the Benioff strain rate per $10,000 \mathrm{~km}^{2}$ in the seismogenic and critical region, respectively. The circular seismogenic region [expressed by relation (4)] is also the region where all previous mainshocks are located. The following two relations hold also for the decelerating and accelerating preshock sequences:

\section{Equation 6}

$\log \left(\mathrm{t}_{\mathrm{c}}-\mathrm{t}_{\mathrm{sd}}\right)=2.95-0.31 \log _{\mathrm{s}_{\mathrm{d}}} \quad \sigma=0.12$

\section{Equation 7}

$\log \left(\mathrm{t}_{\mathrm{c}}-\mathrm{t}_{\mathrm{sa}}\right)=4.60-0.57 \log _{\mathrm{a}} \quad \sigma=0.17$ 
where, $t_{\mathrm{sd}}$ and $\mathrm{t}_{\mathrm{sa}}$ are the start times (in years) of the decelerating and accelerating preshock sequence, respectively, and $t_{c}$ is the origin time of the ensuing mainshock.

The D-AS model is also applied for prediction of ensuing mainshocks. Thus, as predicted epicenter $\mathrm{E}_{\mathrm{d}}(\varphi, \lambda)$ of an ensuing mainshock by the D-AS model is considered the geographic mean (mean latitude, mean longitude) of the epicenters of the decelerating preshocks. Two magnitude values are calculated by the D-AS model $\left(\mathrm{M}_{\mathrm{d}}, \mathrm{M}_{\mathrm{a}}\right)$ by relations 4 and 5 and two values of the origin time, $\mathrm{t}_{\mathrm{c}}$, by relations 6 and 7 .

Strong evidence supporting the validity of the D-AS model is that this model has been successfully tested backwards by fitting data on preshocks which preceded many strong $(\mathrm{M}=6.5-9.0)$ recent (1980-2012) earthquakes that comprise nine complete samples of mainshocks occurred globally (Papazachos et al., 2014). The model has been successfully tested against synthetic catalogues with spatiotemporal clustering (Papazachos et al., 2006; Karakaisis et al., 2013). Using this model, two strong mainshocks of the Aegean area (where relative monitoring is systematic) were successfully predicted. The first case concerns a strong earthquake occurred in the southwestern Aegean (Papazachos et al., 2007) and the other a strong earthquake occurred in the southeastern Aegean (Papazachos et al., 2009).

\section{Backward and forward tests of the two models}

The predictive ability of the joint application of the two models is supported by the fact that both models give similar results although they are based on different physical principles and their applications require different data sets. However, their predictive ability must be tested on already occurred mainshocks (backward tests) and on expected (ensuing) mainshocks (forward tests) because such tests give further evidence for their predictive ability.

Backward tests are made through retrospective prediction of the last strong mainshock occurred in each of the eight circular seismogenic sources of the Aegean Area (defined in section 2). The purpose of these backward tests is to define the uncertainties of the joint application of the two models in the estimated (predicted) origin time, $\Delta \mathrm{t}$, magnitude $\Delta \mathrm{M}$, and epicenter location, $\Delta \mathrm{x}$. Thus: a) The estimated (predicted) origin time is the average of four values [two calculated by relation 1 of the TIMAPR model using the available two complete data samples and two by relations 6 and 7 of the D-AS model], b) the estimated (predicted) moment magnitude is the average of four values [two calculated by relation 2 of the TIMAPR model based on the two complete data samples and other two by relations 4 and 5 of the D-AS model], c) the estimated (predicted) epicenter location is the geographic mean (mean latitude, mean longitude) of three locations [two obtained by the geographic mean of the epicenters defined by the two complete samples of mainshocks used in the TIMAPR model and one determined by the D-AS model (geographic mean of the epicenters of decelerating preshocks)].

The first four columns of Table 2 give the code number of the seismogenic sources, the observed origin time, $t_{c}$, magnitude, $M$, and epicenter coordinates, $E(\varphi, \lambda)$, of the last mainshock occurred in each source. The next three columns list the retrospectively calculated (predicted) parameters by the joint application of the two models. The one standard deviation, $\sigma_{t}$, of the mean time difference and, $\sigma_{m}$, of the mean magnitude difference as well as the mean distance, $x$ (in $\mathrm{km}$ ), between observed and predicted epicenters and its standard deviation, $\sigma_{x}$, are given by the relations:

\section{Equation 8}

$\sigma_{\mathrm{t}}=2.1$ years $\quad \sigma_{\mathrm{m}}=0.2 \quad \mathrm{x}=80 \mathrm{~km} \quad \sigma_{\mathrm{x}}=30 \mathrm{~km}$

The next three columns of Table 2 show the estimated (predicted) by both models values of the origin time, $t_{c}{ }^{*}$, moment magnitude, $\mathbf{M}^{*}$, and epicenter coordinates, $E^{*}(\varphi, \lambda)$, of the shallow $(\mathrm{h} \leq 100 \mathrm{~km})$ mainshocks, probably expected during the period 2015-2024, in each of the eight seismogenic sources of the Aegean area. It must be also noticed that the number eight (8) of 
mainshocks expected during the next decade in the Aegean area is reasonable, because this number is equivalent to the mean number of mainshocks per decade occurred in this area during the instrumental period (1911-2014).

Table 2 - Results of backward and forward tests for the prediction of mainshocks in each of the eight seismogenic sources of the broader Aegean area $\left(34^{0}-42^{0} \mathrm{~N}, 19^{0}-28^{0} \mathrm{E}\right)$. The $\mathrm{t}_{\mathrm{c}}, \mathrm{M}$, $\mathrm{E}(\varphi, \lambda)$ are the origin time, the magnitude and the epicentral coordinates of the past last mainshock in each of these eight seismogenic sources. The $t_{b}, M_{b}, E_{b}(\varphi, \lambda)$ are the corresponding retrospectively predicted parameters for these last eight already occurred mainshocks. The $t_{c}{ }^{*}, M^{*}, E^{*}(\varphi, \lambda)$ are the calculated (predicted) parameters of the expected (ensuing) mainshocks in each of the eight seismogenic sources. The last four columns list the strike angle, $\zeta$, the dip angle, $\theta$, the rake angle, $\lambda$, and the length, $L$ (in $\mathrm{km}$ ), of the seismic fault where each corresponding mainshock is expected to occur.

\begin{tabular}{|c|c|c|c|c|c|c|c|c|c|c|c|c|c|}
\hline $\mathbf{n}$ & $\mathbf{t}_{\mathbf{c}}$ & $\mathbf{M}$ & $\mathbf{E}(\boldsymbol{\varphi}, \boldsymbol{\lambda})$ & $\mathbf{t}_{\mathbf{b}}$ & $\mathbf{M}_{\mathbf{b}}$ & $\mathbf{E}_{\mathbf{b}}(\boldsymbol{\varphi}, \boldsymbol{\lambda})$ & $\mathbf{t}_{\mathbf{c}}{ }^{*}$ & $\mathbf{M}^{*}$ & $\mathbf{E}^{*}(\boldsymbol{\varphi}, \boldsymbol{\lambda})$ & $\boldsymbol{\zeta}^{\boldsymbol{0}}$ & $\boldsymbol{\theta}^{\boldsymbol{0}}$ & $\boldsymbol{\lambda}^{\boldsymbol{0}}$ & $\boldsymbol{L}$ \\
\hline 1 & 13.05 .1995 & 6.5 & $40.2,21.7$ & 1991.9 & 6.6 & $40.3,20.9$ & 2018.8 & 6.7 & $40.1,20.8$ & 196 & 49 & -87 & 21 \\
\hline 2 & 14.08 .2003 & 6.3 & $39.0,20.6$ & 2004.8 & 6.8 & $38.8,20.5$ & 2021.4 & 6.8 & $38.9,20.8$ & 30 & 77 & 178 & 38 \\
\hline 3 & 14.02 .2008 & 6.8 & $36.5,21.7$ & 2004.3 & 6.6 & $36.7,22.2$ & 2021.7 & 6.7 & $36.5,21.7$ & 320 & 32 & 106 & 90 \\
\hline 4 & 15.07 .2008 & 6.4 & $35.8,27.9$ & 2008.5 & 6.6 & $36.3,26.7$ & 2021.2 & 6.9 & $35.3,25.9$ & 10 & 47 & -98 & 65 \\
\hline 5 & 26.07 .2001 & 6.4 & $39.1,24.4$ & 2001.9 & 6.5 & $39.3,23.6$ & 2022.1 & 7.0 & $38.6,22.3$ & 85 & 40 & -125 & 40 \\
\hline 6 & 06.11 .1992 & 6.1 & $38.1,27.0$ & 1990.3 & 6.3 & $38.6,26.5$ & 2017.9 & 7.0 & $39.1,26.0$ & 45 & 89 & -172 & 50 \\
\hline 7 & 13.05 .1995 & 6.5 & $40.2,21.7$ & 1996.5 & 6.3 & $40.6,23.2$ & 2020.8 & 6.7 & $39.6,23.9$ & 225 & 89 & -172 & 90 \\
\hline 8 & 26.07 .2001 & 6.4 & $39.1,24.4$ & 2003.0 & 6.5 & $39.6,24.6$ & 2016.2 & 7.0 & $40.5,26.9$ & 245 & 80 & 165 & 105 \\
\hline
\end{tabular}

\section{Seismic faults of ensuing strong earthquakes in the Aegean}

During the application of the D-AS model on strong $(M \geq 6.5)$ recent (1980-2008) mainshocks in the Aegean, it was observed that most of the epicentres of decelerating preshocks (about 55\%) with magnitude $M \geq 5.0$ were clustered along the strike of the fault where the epicenter of the ensuing mainshock is also located. An example of such preshock clustering is shown in Figure 3 where most of the $M \geq 5.0$ decelerating preshocks (red triangles), which preceded the February 14, 2008 mainshock $(M=6.8)$, are located along the strike of the fault where this mainshock occurred. Since the basic fault parameters (strike, $\zeta$; dip, $\theta$; rake, $\lambda)$ of all known strong $(\mathrm{M} \geq 6.5)$ mainshocks that occurred since antiquity in the Aegean area have been accurately defined by geophysical (fault plane solutions, etc.) and geological (surface fault traces, etc.) methods (Papazachos et al., 2001), an attempt was made to identify that seismic fault within each seismogenic source where the next mainshock is expected to occur. The basic parameters of these faults are listed in the last four columns in Table 3.

\section{Conclusion}

Based on the available relative seismotectonic information for the Aegean area, as well as on the quasi-periodic behavior of mainshocks, eight circular seismogenic sources (networks of active seismic faults) were identified in this area. In each of these sources the predictive properties of two time dependent seismicity models, i.e. the TIMAPR model, based on predictive properties of interevent times of mainshocks, and the D-AS model based on predictive properties of decelerating and accelerating preshocks, were examined. We found that each of the eight seismogenic sources is separated in two zones of different seismicity level: an inner seismically active circular zone $\left(K_{i}\right.$, $r=100 \mathrm{~km})$ and an outer zone $\left(K_{i}, r=100-200 \mathrm{~km}\right)$ with low seismicity.

The joint application of these two models for the estimation (retrospective prediction) of the last strong $(M \geq 6.0)$ mainshock in each of the eight circular seismogenic sources of the Aegean area shows reasonable uncertainties. This supports the validity of the procedure (method) followed in the present work for intermediate term prediction of strong mainshocks. For this reason, this method 
has been also applied to calculate (predict) the parameters of the next strong mainshock in each of the eight seismogenic sources of the Aegean area. It has to be noted that the estimated (predicted) epicenters of these eight (8) expected strong mainshocks in the Aegean area during the time period 2015-2024 are all located within the inner circular parts of the corresponding eight seismogenic sources. This is a reasonable result because past strong earthquakes of the broad Aegean area occurred mainly in these eight inner circular zones, that is, in zones where very active large seismic faults are mainly located.

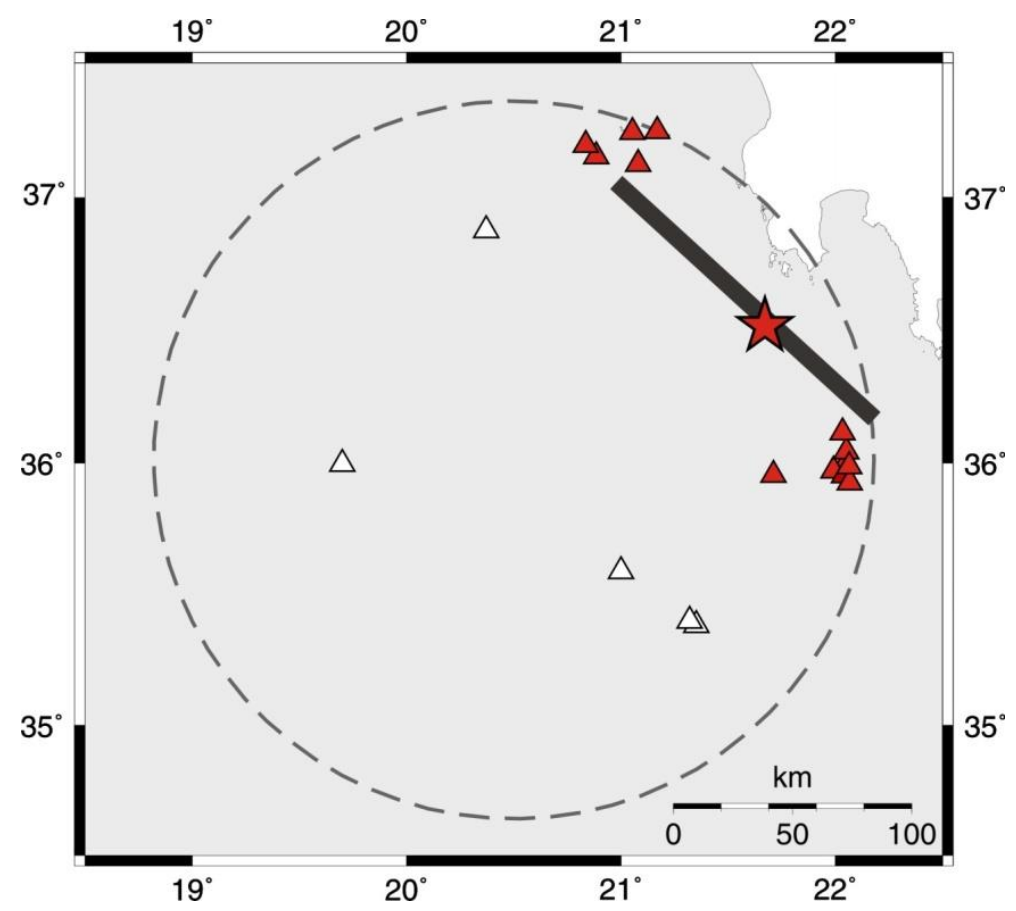

Figure 3 - Identification of the seismic fault $\left(\zeta=331^{0}, \theta=6^{0}, \lambda=117^{0}\right.$, according to GCMT) which generated the strong mainshock $\left(14-2-2008,36.5^{\circ} \mathrm{N}, 21.7^{\circ} \mathrm{E}, M=6.8\right)$. This identification is based on the clustering of most of the epicentres of strong decelerating preshocks (red triangles, $M \geq 5.0$ ) along the strike of a known (Papazachos et al., 2001) seismic fault (thick black line).

The circle marks the seismogenic region where the decelerating preshocks occurred.

It was also observed that most of the decelerating preshocks tend to cluster along the strike of the fault where the impending mainshock will occur. This observation may help to the definition of the faults where the next mainshocks will probably be generated, thus facilitating seismic hazard assessment studies.

\section{Acknowledgments}

This work was supported by the THALES Program of the Ministry of Education of Greece and the European Union in the framework of the project entitled "Integrated understanding of Seismicity, using innovative Methodologies of Fracture mechanics along with Earthquake and nonextensive statistical physics - Application to the geodynamic system of the Hellenic Arc. SEISMO FEAR HELLARC". Thanks are also due to Wessel and Smith (1998) for freely distributed the GMT software used to produce the maps of this paper. 


\section{References}

Algermissen, S.T., Perkins, D.M., Isherwood, P.W., Gordon, D., Reagor, G. and Howard, C., 1976. Seismic risk evaluation of the Balkan region, Proc., Sem. Seismic zoning maps, Skopje 27 Oct- 4 Nov., 1975, 2, 171-219.

Bufe, C.G. and Varnes, D.J., 1993. Predictive modeling of seismic cycle of the Great San Francisco Bay Region, J. Geophys. Res., 98, 9872-9883.

Jaumè, S.C. and Sykes, L.R., 1999. Evolving towards a critical point: a review of accelerating seismic $\mathrm{m}$ oment/energy release prior to large and great earthquakes, Pure Appl. Geophys., 155, 279-309.

Karakaisis, G.F., Papazachos, C.B., Scordilis, E.M. and Papazachos, B.C., 2010. Seismic Sources and seismic faults in the Aegean Area, Bull. Geol. Soc. Greece, XLIII/1, 2026-2042.

Karakaisis, G.F., Papazachos, C.B. and Scordilis, E.M., 2013. Recent reliable observations and improved tests on synthetic catalogs with spatiotemporal clustering verify precursory decelerating-accelerating seismicity, J. Seismology, DOI 10.1007/s10950-013-9372-5.

Mc Kenzie, D.F., 1970. The plate tectonics of the Mediterranean, Nature, 226, 239-243.

Mignan, A., 2011. Retrospective on the Accelerating Seismic Release (ASR) hypothesis: Controversy and new horizons, Tectonophysics, 505, 1-16

Papazachos, B.C. and Comninakis, P.E., 1971. Geophysical and tectonic features of the Aegean arc, J. Geophys.Res., 76, 9817-8539.

Papazachos, B.C. and Papaioannou, Ch.A., $1993 . \quad$ Longterm earthquake prediction in the Aegean area based on a time and magnitude predictable model, Pure Appl. Geophys., 140, 595-612.

Papazachos, B.C., Mountrakis, D.M., Papazachos, C.B., Tranos, M.D., Karakaisis, G.F. and Savvaidis, A.S., 2001.The faults which generated the known strong earthquakes in Greece from the $5^{\text {th }} \mathrm{BC}$ century till now, Proc. $2^{\text {nd }}$ Symposium on Engineering Seismology and Earthquake Engineering, Thessaloniki, 28-30 November 2001, 2, 17-26.

Papazachos, B.C., Karakaisis, G.F., Papazachos, C.B. and Scordilis, E.M., 2007. Evaluation of the results for an intermediate term prediction of the $8^{\text {th }}$ January 2006, M=6.9 Cythera earthquake in Southwestern Aegean, Bull. Seism. Soc. Am., 97, 1B, 347-352.

Papazachos, B.C., Karakaisis, G.F., Papazachos, C.B., Panagiotopoulos, D.G. and Scordilis, E.M., 2009. A forward test of the Decelerating-Accelerating Seismic Strain Model in the Mediterranean, Boll. Geof. Teor. Appl., 50, 3, 235-254.

Papazachos, B.C., Karakaisis, G.F., Papazachos, C.B. and Scordilis, E.M., 2011. Tests of two time dependent seismicity models based on interevent times of mainshocks and on seismic triggering in the Aegean Area, Boll. Geof. Teor. Appl., 52, 32-57.

Papazachos, B.C., Karakaisis, G.F. and Scordilis, E.M., 2014. Time dependent seismicity in the continental fracture system, Boll. Geof. Teor. Appl., DOI 10.4430/bgta0117.

Papazachos, C.B., Karakaisis, G.F., Scordilis, E.M. and Papazachos, B.C., 2006. New observational information on the precursory accelerating and decelerating strain energy release, Tectonophysics, 423, 83-96.

Wessel, P. and Smith, W., 1998. New, improved version of the Generic Mapping Tools released, EOS Trans. AGU, 79, 579. 